\title{
EFFECT OF MYCORRHIZAL INOCULATION AND METHANOL SPRAYING ON SOME PHOTOSYNTHETIC CHARACTERISTICS AND YIELD IN WHEAT CULTIVARS UNDER END-SEASON DROUGHT STRESS
}

\author{
SAYYAHFAR, M. ${ }^{1}$ - MIRSHEKARI, B. ${ }^{1 *}-$ YARNIA, M. ${ }^{1}-$ FARAHVASH, F. ${ }^{1}$ - ESMAEILZADEH \\ MOGHADAM, $\mathrm{M}^{2}$ \\ ${ }^{I}$ Department of Agronomy and Plant Breeding, Tabriz Branch, Islamic Azad University, Tabriz, \\ Iran \\ ${ }^{2}$ Seed and Plant Improvement Research Institute, Agricultural Research, Education and \\ Extension Organization (AREEO), Karaj, Iran \\ *Corresponding author \\ e-mail: Mirshekari@iaut.ac.ir; phone: +98-914-316-8208; fax:+98-411-637-0009 \\ (Received $9^{\text {th }}$ Feb 2018; accepted $31^{\text {st }}$ May 2018)
}

\begin{abstract}
A two-year study was carried out with split-plot factorial arrangement based on randomized complete block design in three replications in Khorramabad, Iran, during 2012-2014. The studied factors in the main-plots included end season drought stress at three levels (normal irrigation, mild stress and severe stress with irrigation based on $40 \%, 60 \%$ and $80 \%$ moisture depletion of soil water available to plants) and mycorrhizal biofertilizer factors and methanol spraying at four levels (without mycorrhiza inoculation + distilled water spraying, control; mycorrhiza inoculation + distilled water spraying; without mycorrhiza inoculation + methanol spraying; and mycorrhiza inoculation + methanol spraying). Moreover, the three irrigated wheat cultivars Aflak, Dena and Alvand with factorial arrangement were in sub-plots. Results demonstrated that drought stress decreased stomatal conductance, leaf transpiration, photosynthesis rate and grain yield. Crop plants under mild stress conditions experienced lower carbon dioxide in sub-stomatal chamber, whereas, its accumulation in those plants that were under severe stress conditions increased significantly. The studied cultivars responded to drought stress differently. Yield reduction in Alvand was more severe than in Aflak and Dena under mild and severe drought stress conditions. The results suggested that mycorrhizal inoculation and methanol spraying play an important role in enhancing drought tolerance in susceptible wheat cultivars to drought stress. Moreover, they can be used in irrigated wheat farming to reduce damages caused by end season drought stress.
\end{abstract}

Keywords: irrigation, photosynthesis, severe stress, transpiration, methanol spraying, wheat

\section{Introduction}

As the most important cereal in many parts of the world, wheat is the main food for most people (Rauf et al., 2007; Shewry, 2009). Wheat is one of the most important cereal crop and considered as a staple food of the vast majority of the human population including urban and rural societies and it is also a major source of straw for animal feeding (Sharma et al., 2012).

Drought is one of the critical environmental adversities affecting the growth, development and final yield of crop species (Geng et al., 2016; Daryanto et al., 2017), and the frequency and severity of drought stress events are expecting to increase due to global climate change (Cook et al., 2014; Zhao and Dai, 2015; Joshi et al., 2016). Drought stress perturbs a broad range of plant physiological and biochemical processes, including decreased plant water status, inhibited photosynthetic processes, induced oxidative stress damage and so on, which ultimately lead to growth retardation and the 
reduction of crop yield (Perdomo et al., 2015; Saeidi and Abdoli, 2015; Daryanto et al., 2017). Drought stress is one of the major problems in successful crop production throughout the world (Auge, 2001) as well as in Iran. Drought stress is a key environmental phenomenon affecting cereal yields, often occurs over the wheat grain filling period, and eventually reduces crop yield in most cultivated areas in the world (Altenbach et al., 2003). In Iran, a significant portion of the 2.4 million hectares of irrigated wheat is damaged due to drought stress during flowering and grain filling phases (Jalal Kamali et al., 2012).

Crop growth is reduced under drought stress conditions due to limited photosynthetic rate. The damage caused by drought is primarily attributed to the inhibition and disruption of photosynthesis, which is the main mechanism of plant growth and maintenance of natural environments, and it threats the growth and yields of plants (Shao et al., 2016). Water deficit is often complemented by high temperatures that increase evapotranspiration and affect photosynthesis and ultimately decrease yield (Mir et al., 2012). Water deficit affects photosynthesis negatively by changing inner structure of the chloroplast, mitochondria and chlorophyll content and minerals (Huseynova et al., 2016). Allahverdiyev and Huseynova (2017) reported that stomatal conductance, net photosynthesic rate and transpiration rate decreased significantly in flag leaves of wheat genotypes in response to drought stress at anthesis. The intercellular $\mathrm{CO}_{2}$ concentration in flag leaf of most genotypes increased under drought condition. Mild drought stress reduces photosynthesis through reversible stomatal factors. Under more severe or prolonged stress conditions, non-stomatal factors aggravate unfavorable conditions and the effects of stress generally become irreversible (Ahmadi and Baker, 2000). Blum et al. (1981) suggested that those genotypes are suitable for dry regions that are capable of retaining more water without closing their stomata.

Since crops production and, therefore, food security depend on the management of limiting factors, it is necessary to develop efficient strategies that allow the improvement of crop yield under water deficit stress (FAO, 2012). Water is undisputedly the major factor for the declining food production in many parts of the world, particularly in the arid and semiarid regions. Consequently, the world is now being challenged to produce "more crop per drop" of water. Therefore, in recent years there are increasing numbers of studies to understand the mechanism by which plants alleviate drought stress, and arbuscular mycorrhizal (AM) fungi seems to be an excellent alternative to serve the purpose. However, the mechanism by which AM fungi promotes drought tolerance is still to be understood well (Dar et al., 2018). Recently, it has been observed that the symbiotic interaction of plants with AMF, in addition to being important from the agricultural and ecological point of view (Yang et al., 2008), could be a sustainable mitigation practice for water deficit stress (Aroca, 2012). AM fungi allow host plants to grow more efficiently under biotic and abiotic stress conditions (Gholamhoseini et al., 2013). A recent finding indicates that AM fungus have a key role in modifications of root hairs consequently helping the plants to overcome the drought (Li et al., 2014). In association with symbiotic AM fungi, plants could explore larger volumes of soil to absorb water and nutrients thereby impart stress tolerance to the plants (Smith et al., 2009). Arbuscular mycorrhizal (AM) symbiosis often modifies gas exchange of the host plant (Koide, 1993; Smith and Read, 2008; Ruiz-Lozano and Aroca, 2010; Auge et al., 2014). Mycorrhizal association has been shown to increase the carbon fixation abilities of the plants. In a number of systems, higher photosynthetic rates have been reported when the plants are in association with 
AM fungi. For instance, in black locust, Yang et al. (2014) observed high stomatal conductance, high transpiration rates and high photosynthetic rates with reduced internal $\mathrm{CO}_{2}$ concentration in fungal colonized plants than the non-colonized plants. Such higher photosynthetic rate as a consequence of fungal association has also been reported by Zhu et al. (2012). They observed high photosynthetic and transpiration rates in AM fungi colonized plants of maize than in non-colonized plants both under control and drought stress conditions. Arbuscular mycorrhiza stimulation of carbon exchange rate, stomatal conductance, and transpiration rate has been significantly associated with mycorrhizal stimulation of shoot dry weight, leaf phosphorus, leaf nitrogen:phosphorus ratio, and percent root colonization. (Auge et al., 2016). This relationship between the stomatal opening and the relative increase in the photosynthetic activity have been described in corn (Estrada et al., 2013),

Studies over recent years revealed that growth and yield of $\mathrm{C}_{3}$ plants improved by methanol spraying, and methanol can be considered a carbon source for such plants. In general, the main contribution of these substances is to reduce the effects that stresses induced on crops have in performing photorespiration (Downie et al., 2004). Since nearly $90 \%$ of plant dry matter results from carbon dioxide assimilation through photosynthesis, an increase in photosynthesis rate can boost the crop production capacity (Makhdum et al., 2002). Methanol is a carbon source therefore increases $\mathrm{CO}_{2}$ concentrations in plants and enhances growth and yield because the most important factor that affects dry weight of plants is $\mathrm{CO}_{2}$ assimilation through photosynthesis (Mirakhori et al., 2009). Higher photosynthetic capacity can be achieved by using compounds including methanol, ethanol, propanol, and butanol as well as amino acids including glycine, glutamate and aspartate (Ramberg et al., 2002). In plants facing drought stress, methanol spraying prevents reduction of biomass (Rajala et al., 1998).

This study attempted to determine the effect of end season drought stress on yield and on photosynthesis and leaf gas exchange in three wheat cultivars so as to identify cultivars that are susceptible or tolerant to end season drought stress. Moreover, this study intended to analyze and clarify the effect of mycorrhiza inoculation and methanol spraying on wheat yield and leaf gas exchanges in an effort to mitigate and moderate the adverse effects of drought stress.

\section{Materials and methods}

\section{Experimental site and treatments}

A two-year experiment was carried out with split-plot factorial arrangement based on randomized complete block design in three replications in Khorramabad $\left(33^{\circ} 20^{\prime} \mathrm{N}\right.$ $48^{\circ} 21^{\prime} \mathrm{E}$, altitude $=1171 \mathrm{~m}$ ), Iran, during 2012-2014. The main factor included end season drought stress at three levels (normal irrigation, mild stress and severe stress with irrigation based on $40 \%, 60 \%$ and $80 \%$ moisture depletion of soil water available to plants) and factorial combination of mycorrhizal inoculation and methanol spraying (non-inoculation + non-praying as control; mycorrhizal inoculation; methanol spraying; mycorrhizal inoculation + methanol spraying) with wheat cultivars of Aflak, Dena and Alvand considered as sub factors. The climatic parameters (annual and long-term) of the experimental site are presented in Table 1 during cropping years 2012-2013 and 20132014. 
Table 1. The climatic parameters of the experimental site during cropping years 2012-2013 and 2013-2014 and average of 30 years (long-term)

\begin{tabular}{|c|c|c|c|c|c|c|c|c|c|c|c|c|c|c|c|}
\hline \multirow[b]{3}{*}{ Month } & \multicolumn{5}{|c|}{ 2012-2013 cropping year } & \multicolumn{5}{|c|}{ 2012-2013 cropping year } & \multicolumn{5}{|c|}{ Average of 30 years (long-term) } \\
\hline & \multirow[b]{2}{*}{ 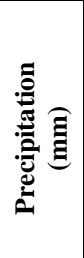 } & \multirow[b]{2}{*}{ 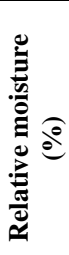 } & \multicolumn{3}{|c|}{ Temperature $\left({ }^{\circ} \mathrm{C}\right)$} & \multirow[b]{2}{*}{ 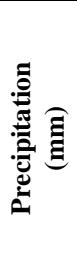 } & \multirow[b]{2}{*}{ 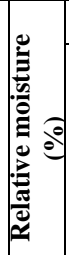 } & \multicolumn{3}{|c|}{ Temperature $\left({ }^{\circ} \mathbf{C}\right)$} & \multirow[b]{2}{*}{ 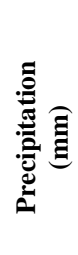 } & \multirow[b]{2}{*}{ 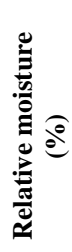 } & \multicolumn{3}{|c|}{ Temperature $\left({ }^{\circ} \mathrm{C}\right)$} \\
\hline & & & 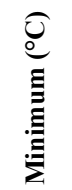 & 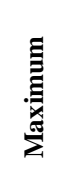 & 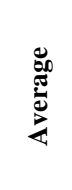 & & & 韾 & 声 & 总 & & & 声 & 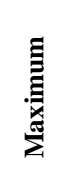 & 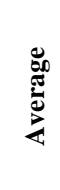 \\
\hline October & 2.6 & 26.3 & 6.2 & 34.8 & 21.4 & 0 & 26 & 1.8 & 33.4 & 18.9 & 10.2 & 34.7 & 0 & 32 & 20.7 \\
\hline November & 59 & 59.8 & 1.8 & 27.4 & 14.6 & 69.6 & 60 & 1.2 & 27.2 & 13 & 53.4 & 51.6 & -7.8 & 25 & 14.4 \\
\hline December & 30 & 69.9 & -3.6 & 18.4 & 7.8 & 71.6 & 65 & -4.6 & 20.8 & 8.3 & 77.6 & 62.6 & -8 & 9.6 & 8.6 \\
\hline January & 72.9 & 61.5 & -6.2 & 17.2 & 5.3 & 70.8 & 63 & -7 & 16.6 & 4.1 & 77.6 & 66.6 & -13.6 & 17.6 & 5.9 \\
\hline February & 68.4 & 59.8 & -4.6 & 20.6 & 8.3 & 40.8 & 61 & -7.6 & 18.8 & 5.9 & 83.5 & 66.1 & -14.6 & 18 & 6.3 \\
\hline March & 28.3 & 54.7 & -3 & 25.6 & 10.6 & 68.4 & 61 & -2 & 22.4 & 10.6 & 81.3 & 58.7 & -11 & 24 & 9.9 \\
\hline April & 29.8 & 47.5 & 0.6 & 27.4 & 14.9 & 86.9 & 57 & -1.4 & 29.8 & 13 & 78.5 & 56.8 & -7 & 33 & 13.7 \\
\hline May & 72.4 & 52.8 & 3.2 & 30.6 & 17.2 & 22.8 & 48 & 5.8 & 33.6 & 19.5 & 56.8 & 50.6 & -1.8 & 37 & 18.4 \\
\hline June & 0.2 & 24.9 & 10.6 & 41.2 & 24.2 & 2 & 35 & 9.6 & 36.6 & 23.4 & 5.1 & 33.4 & 5 & 43 & 24.2 \\
\hline Sum & 363.6 & & & & & 432.9 & & & & & 525.6 & & & & \\
\hline
\end{tabular}

Two bread wheat (Triticum aestivum L.) cultivars of Aflak and Alvand are spring and intermediate types, respectively, and Dena, as durum wheat ( $T$. durum L.) cultivar, has a spring growth habit (Saeidi et al., 2005). The studied cultivars have been introduced by the Agricultural Research, Education and Extension Organization (AREEO) in the past few years, and are cultivated in temperate, tropical and subtropical regions of Iran. The mycorrhiza bio-fertilizer was a combination of two mycorrhiza fungi species called Funnelifomis mosseae and Rhizophagus intaradices and contained 15 spores $\mathrm{g}^{-1}$ and 930 hyphae of mycorrhiza cm${ }^{-3}$. Before sowing, Mycorrhiza (40 kg ha${ }^{1}$ ) was poured uniformly into the sowing lines at the depth of 6-7 cm. Sowing density was 450 seeds $\mathrm{m}^{-2}$. Each sub-plot consisted of 6 sowing lines with a spacing of $20 \mathrm{~cm}$. The area of each plot was $7.2 \mathrm{~m}^{2}$.

Prior to sowing, the soil was sampled to determine its physical and chemical characteristics (Table 2). Based on the soil analysis results, the chemical fertilizers of urea, triple super phosphate and potassium chloride were applied at 200, 100 and $50 \mathrm{~kg}$ $\mathrm{ha}^{-1}$, respectively. Given the conventional practices in the region and the amount of regional rainfall, irrigation operations were carried out if necessary in all the experimental plots uniformly prior to beginning stage of stress treatments. At the wheat spike emergence phase, the normal irrigation and stress treatments were applied. Irrigation in normal irrigation and stress treatments were based on moisture depletion of soil in the range of field capacity to permanent wilting point. Soil moisture depletion percentage was measured by a Time Domain Reflectometer (TDR), which determines the volumetric percentage of soil moisture at the desired depth. Irrigation water volume for normal irrigation, mild stress and severe stress was $185,132.5$ and $80 \mathrm{~mm}$, respectively in cropping year 2012-2013, and this amount was 147.5, 90 and $42.5 \mathrm{~mm}$, respectively in cropping year 2013-2014. Industrial methanol (98\%) at the concentration of $20 \% \mathrm{v} / \mathrm{v}$ was sprayed at spike emergence three times at 10-days intervals. Moreover, to each liter of the methanol solution, $1 \mathrm{~g}$ of the amino acid glycine and $1 \mathrm{mg}$ of tetrahydrofolate were added. 
Table 2. Soil physical and chemical characteristics at the experimental site

\begin{tabular}{|c|c|c|c|c|c|c|c|c|c|c|c|c|c|c|}
\hline \multirow{2}{*}{ Year } & \multirow{2}{*}{$\begin{array}{c}\text { Soil } \\
\text { texture }\end{array}$} & \multicolumn{3}{|c|}{ Soil particles } & \multirow{2}{*}{ pH } & \multirow{2}{*}{$\begin{array}{c}\mathbf{E C} \\
(\mathbf{d S} / \mathbf{m})\end{array}$} & \multirow{2}{*}{$\begin{array}{l}\text { O.C. } \\
(\%)\end{array}$} & \multirow{2}{*}{$\begin{array}{c}\mathbf{N} \\
(\%)\end{array}$} & \multirow{2}{*}{$\begin{array}{c}\mathbf{P} \\
(\mathbf{m g} / \mathbf{k g})\end{array}$} & \multirow{2}{*}{$\begin{array}{c}\mathrm{K} \\
(\mathrm{mg} / \mathrm{kg})\end{array}$} & \multirow{2}{*}{$\begin{array}{c}\mathrm{Zn} \\
(\mathrm{mg} / \mathrm{kg})\end{array}$} & \multirow{2}{*}{$\begin{array}{c}\text { B } \\
(\mathrm{mg} / \mathrm{kg})\end{array}$} & \multirow{2}{*}{$\begin{array}{c}\mathrm{Cu} \\
(\mathrm{mg} / \mathrm{kg})\end{array}$} & \multirow{2}{*}{$\begin{array}{c}\text { Fe } \\
(\mathbf{m g} / \mathbf{k g})\end{array}$} \\
\hline & & Sand & Silt & Clay & & & & & & & & & & \\
\hline 2012 & $\begin{array}{l}\text { Loam } \\
\text { clay }\end{array}$ & 20 & 57 & 23 & 7.7 & 0.77 & 1.02 & 0.098 & 8.8 & 332 & 0.33 & 0.2 & 1.6 & 4.8 \\
\hline 2013 & $\begin{array}{l}\text { Loam } \\
\text { clay }\end{array}$ & 20 & 57 & 23 & 7.8 & 0.81 & 1.08 & 0.101 & 8.6 & 335 & 0.31 & 0.2 & 1.6 & 4.6 \\
\hline
\end{tabular}

\section{Leaf gas exchange measurement}

The photosynthesis and leaf gas exchange measurements on the field were made by using a portable gas analyzer (ADC, Hoddeston UK, model LCA4) to measure the photosynthesis rate per leaf area unit $\left(\mu \mathrm{mol} \mathrm{CO} \mathrm{Cm}^{-2} \mathrm{~s}^{-1}\right)$, stomatal conductance (mmol $\left.\mathrm{m}^{-2} \mathrm{~s}^{-1}\right)$, transpiration rate $\left(\mathrm{mmol} \mathrm{H}_{2} \mathrm{O} \mathrm{m} \mathrm{m}^{-2} \mathrm{~s}^{-1}\right)$ and internal $\mathrm{CO}_{2}$ concentration (mmol). Measurements were conducted at $11 \mathrm{AM}$, at $26-27^{\circ} \mathrm{C}$ and at the light intensity of 1100 1200 micromole photon $\mathrm{m}^{-2} \mathrm{~s}^{-1}$. From each plot, five plants were randomly selected. Then, the flag leaves of the selected plants were placed inside a glass container of LCA4 for $40 \mathrm{~s}$ and the related value was read and recorded (Fig. 1). Grain yield was measured at full maturity in the harvesting area of $3 \mathrm{~m}^{2}$ from the middle four rows of each plot. Then, the seeds were weighed for grain yield calculation.

\section{Data analysis}

Combined analysis of the data obtained from two experimental years was performed using the expected value of mean square treatment. Moreover, the variance tests were also performed based on expected value of variance for the sources of variations. ANOVA operations and statistical calculations, comparison of the means, and calculation of simple correlation coefficients of traits were carried out using SAS, SPSS and MSTATC. The diagrams were drawn using Excel, and comparison of the means of the traits was performed employing Duncan's multiple range test (DMRT) at the 5\% probability level.
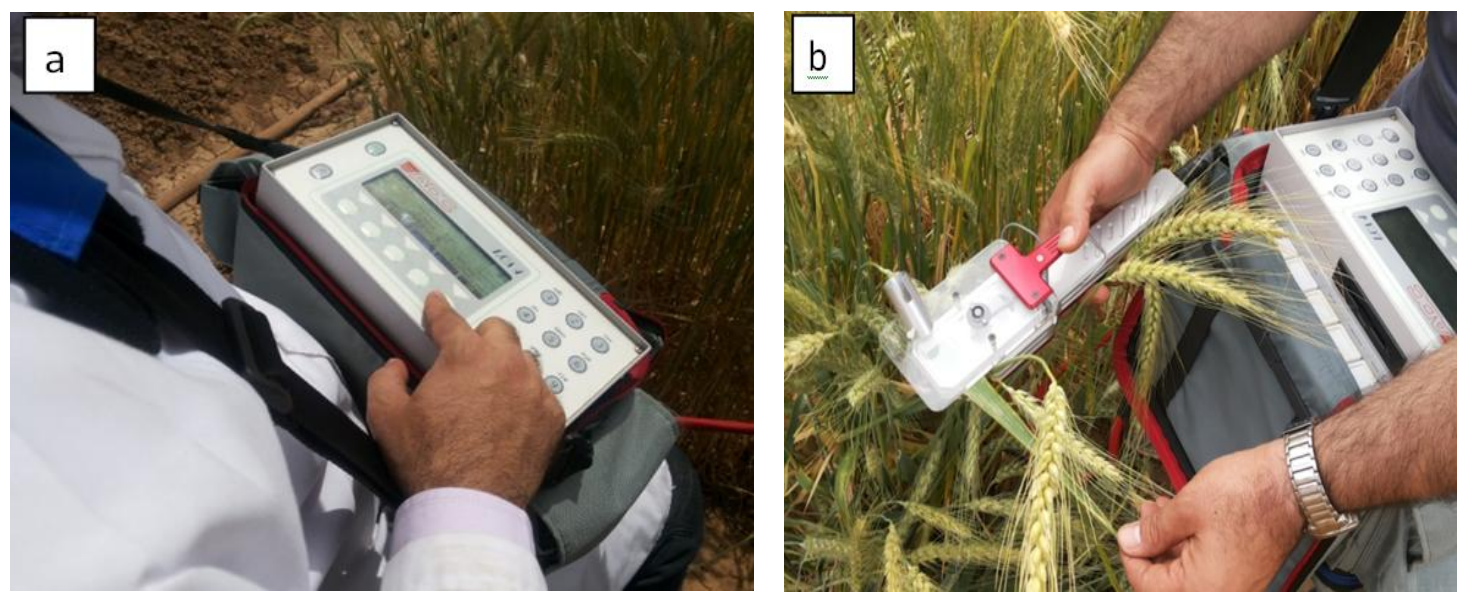

Figure 1. Photos about the portable gas analyzer device (ADC, Hoddeston UK, model LCA4) (a). Measuring flag leaf photosynthesis and gas exchange of wheat plants in experimental plots (b) 


\section{Results}

\section{Leaf gas exchange}

Effect of year on stomatal conductance, leaf transpiration, internal $\mathrm{CO}_{2}$ concentration and photosynthetic rate was significant (Table 3). Stomatal conductance and photosynthetic rate in the second year improved and leaf transpiration and internal $\mathrm{CO}_{2}$ concentration were higher in the first year than in the second year (Table 4) which could be due to variations in climatic conditions among experimental years.

Table 3. Combined analysis of variance (mean squares) on the effect of water deficit stress, mycorrhiza-methanol spraying and cultivar on grain yield, photosynthesis and gas exchanges of wheat flag leaf (two-year analysis)

\begin{tabular}{c|c|c|c|c|c|c}
\hline S.O.V. & D.F. & $\begin{array}{c}\text { Leaf } \\
\text { transpiration }\end{array}$ & $\begin{array}{c}\text { Stomatal } \\
\text { conductance }\end{array}$ & $\begin{array}{c}\text { Internal CO } \\
\text { concentration }\end{array}$ & $\begin{array}{c}\text { Photosynthesis } \\
\text { rate }\end{array}$ & Grain yield \\
\hline Year (Y) & 1 & $50.07^{* *}$ & $654.52^{*}$ & $3918.52^{*}$ & $103.19^{*}$ & $17351561.9 \mathrm{~ns}$ \\
Replication (Year) & 4 & 0.567 & 13.643 & 150.245 & 3.110 & 2420430.2 \\
Water deficit stress (S) & 2 & $262.86^{* *}$ & $298304.03^{* *}$ & $162214.35^{* *}$ & $867.46^{* *}$ & $56711491.26^{* *}$ \\
$\mathrm{~S} \times \mathrm{Y}$ & 2 & $0.06 \mathrm{~ns}$ & $4.95 \mathrm{~ns}$ & $569.45 \mathrm{~ns}$ & $0.022 \mathrm{~ns}$ & $282271717 \mathrm{~ns}$ \\
Error (a) & 8 & 2.226 & 167.130 & 2127.55 & 3.36 & 8946809 \\
Mycorrhiza-methanol (M) & 3 & $26.46^{* *}$ & $13424.46^{* *}$ & $1267.59 * *$ & $84.02^{* *}$ & $5024713.9 * *$ \\
$\mathrm{Y} \times \mathrm{M}$ & 3 & $0.07 \mathrm{~ns}$ & $996.59 \mathrm{~ns}$ & $43.81 \mathrm{~ns}$ & $0.20 \mathrm{~ns}$ & $466122.42 \mathrm{~ns}$ \\
$\mathrm{~S} \times \mathrm{M}$ & 6 & $2.97 * *$ & $14.42^{* *}$ & $3172.06 * *$ & $6.44^{* *}$ & $783005.6 * *$ \\
$\mathrm{Y} \times \mathrm{S} \times \mathrm{M}$ & 6 & $0.023 \mathrm{~ns}$ & $18432.94 \mathrm{~ns}$ & $140.74 \mathrm{~ns}$ & $0.146 \mathrm{~ns}$ & $323121.19 \mathrm{~ns}$ \\
$\mathrm{Cultivar}(\mathrm{V})$ & 2 & $23.74 * *$ & $9.75 \mathrm{~ns}$ & $23.722 \mathrm{~ns}$ & $95.99 * *$ & $43692271.45^{* *}$ \\
$\mathrm{Y} \times \mathrm{V}$ & 2 & $0.06 \mathrm{~ns}$ & $2059.82 \mathrm{~ns}$ & $40.80 \mathrm{~ns}$ & $0.49 \mathrm{~ns}$ & $545193.2 \mathrm{~ns}$ \\
$\mathrm{~S} \times \mathrm{V}$ & 4 & $3.43^{* *}$ & $3.02^{* *}$ & $1963.86^{* *}$ & $11.29 * *$ & $3800573.81 * *$ \\
$\mathrm{Y} \times \mathrm{S} \times \mathrm{V}$ & 4 & $0.005 \mathrm{~ns}$ & $227.15 \mathrm{~ns}$ & $72.56 \mathrm{~ns}$ & $0.04 \mathrm{~ns}$ & $111023.44 \mathrm{~ns}$ \\
$\mathrm{M} \times \mathrm{V}$ & 6 & $0.56 \mathrm{~ns}$ & $4.32 \mathrm{~ns}$ & $80.27 \mathrm{~ns}$ & $0.86 \mathrm{~ns}$ & $596028.2 *$ \\
$\mathrm{Y} \times \mathrm{M} \times \mathrm{V}$ & 6 & $0.023 \mathrm{~ns}$ & $147.61 \mathrm{~ns}$ & $77.22 \mathrm{~ns}$ & $0.113 \mathrm{~ns}$ & $142153.6 \mathrm{~ns}$ \\
$\mathrm{~S} \times \mathrm{M} \times \mathrm{V}$ & 12 & $0.27 \mathrm{~ns}$ & $36.38 \mathrm{~ns}$ & $170.09 \mathrm{~ns}$ & $1.72 \mathrm{~ns}$ & $395060.4 \mathrm{~ns}$ \\
$\mathrm{Y} \times \mathrm{S} \times \mathrm{M} \times \mathrm{V}$ & 12 & $0.014 \mathrm{~ns}$ & $3.98 \mathrm{~ns}$ & $41.60 \mathrm{~ns}$ & $0.069 \mathrm{~ns}$ & $306104.5 \mathrm{~ns}$ \\
$\mathrm{Error}(\mathrm{bc})$ & 132 & 0.508 & 119.36 & 131.17 & 1.21 & 225166.6 \\
$\mathrm{C} . \mathrm{V}$. & & 10.7 & 10.6 & 6.4 & 8.9 & 8.6 \\
\hline
\end{tabular}

$\mathrm{ns}, *$, and $* *$ are non-significant, significant at $5 \%$ and $1 \%$ probability levels, respectively.

Effect of water deficit stress on leaf gas exchange was significant (Table 3). Mild and severe water deficit stress decreased leaf stomatal conductance by $55.5 \%$ and $69.2 \%$, leaf transpiration by $18.6 \%$ and $45.1 \%$ and photosynthetic rate by $15.6 \%$ and $69.2 \%$, respectively, compared to the normal irrigation. Mild stress resulted in $26.6 \%$ decrease in internal $\mathrm{CO}_{2}$ concentration while severe stress resulted in $26.9 \%$ increase in internal $\mathrm{CO}_{2}$ concentration, compared to the normal irrigation (Table 4).

Increasing depletion of plant available water under normal irrigation to $60 \%$ and $80 \%$ of moisture depletion and increasing stress intensity, stomatal conductance and leaf transpiration decreased in all treatments and the highest decreasing observed at 
$80 \%$ depletion of soil available water. The highest decreasing trend was devoted to the control and the lowest was for combined treatment. Under normal irrigation, mild and severe stresses, stomatal conductance and leaf transpiration in mycorrhizal inoculation, methanol spraying and combined treatment were more than control (Figs. $2 a$ and $3 a$ ).

Table 4. Mean comparison results of main effects of year, water deficit stress, mycorrhizamethanol spraying and cultivar on grain yield, photosynthesis and gas exchanges of wheat flag leaf (mean of two years)

\begin{tabular}{|c|c|c|c|c|c|}
\hline Treatments & $\begin{array}{c}\text { Leaf } \\
\text { transpiration } \\
\left(\mathbf{m o l ~ H}_{2} \mathrm{O} \mathrm{m}^{-2} \mathbf{s}^{-1}\right)\end{array}$ & 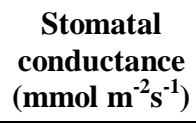 & $\begin{array}{c}\text { Internal } \mathrm{CO}_{2} \\
\text { concentration } \\
\left(\mathbf{m m o l ~} \mathrm{CO}_{2}\right)\end{array}$ & $\begin{array}{c}\text { Photosynthesis } \\
\text { rate } \\
\left(\mu \mathrm{mol} \mathrm{CO}_{2} \mathrm{~m}^{-2} \mathbf{s}^{-1}\right)\end{array}$ & $\begin{array}{c}\text { Grain yield } \\
\left(\mathrm{kg} \mathrm{ha}^{-1}\right)\end{array}$ \\
\hline First year & $7.1 \mathrm{~b}$ & $101 \mathrm{~b}$ & $182.2 \mathrm{a}$ & $11.7 \mathrm{~b}$ & $5234.9 \mathrm{a}$ \\
\hline Second year & $6.1 \mathrm{~b}$ & $104.5 \mathrm{a}$ & $173.7 \mathrm{~b}$ & $13.1 \mathrm{a}$ & $5801.7 \mathrm{a}$ \\
\hline \multicolumn{6}{|l|}{$\begin{array}{l}\text { Water deficit stress } \\
\text { (S) }\end{array}$} \\
\hline Normal irrigation & $8.4 \mathrm{a}$ & $175.8 \mathrm{a}$ & $177.7 \mathrm{~b}$ & $15.5 \mathrm{a}$ & $6373.3 \mathrm{a}$ \\
\hline Mild stress & $6.8 b$ & $78.2 b$ & $130.5 \mathrm{c}$ & $13 b$ & $5580.1 \mathrm{~b}$ \\
\hline Severe stress & $4.6 c$ & $54.2 \mathrm{c}$ & $225.5 \mathrm{a}$ & $8.6 \mathrm{c}$ & $4601.5 c$ \\
\hline \multicolumn{6}{|l|}{$\begin{array}{l}\text { Mycorrhiza- } \\
\text { methanol (M) }\end{array}$} \\
\hline Control & $5.7 \mathrm{c}$ & $82.7 \mathrm{~d}$ & $171.7 \mathrm{c}$ & $10.6 \mathrm{c}$ & $5233.1 \mathrm{c}$ \\
\hline $\begin{array}{c}\text { Mycorrhiza } \\
\text { inoculation (AM) }\end{array}$ & $6.9 \mathrm{~b}$ & 110.2 & $176.8 \mathrm{~b}$ & $12.7 \mathrm{~b}$ & $5574.3 \mathrm{~b}$ \\
\hline $\begin{array}{c}\text { Methanol spraying } \\
\text { (ME) }\end{array}$ & $6.6 b$ & $98.7 \mathrm{c}$ & $180.4 \mathrm{ab}$ & $12.7 \mathrm{~b}$ & $5342.7 \mathrm{c}$ \\
\hline $\mathrm{AM}+\mathrm{ME}$ & $7.3 \mathrm{a}$ & $119.3 \mathrm{a}$ & $182.8 \mathrm{a}$ & $13.5 \mathrm{a}$ & 59230.a \\
\hline \multicolumn{6}{|l|}{ Cultivar (V) } \\
\hline Aflak & $6.8 \mathrm{a}$ & $103.3 b$ & $178 \mathrm{a}$ & $12.8 \mathrm{~b}$ & $5869.4 b$ \\
\hline Dena & 7.1a & $118.4 \mathrm{a}$ & $178.4 \mathrm{a}$ & $13.4 \mathrm{a}$ & $6059.9 \mathrm{a}$ \\
\hline Alvand & $6 b$ & $86.5 \mathrm{c}$ & $177.3 \mathrm{a}$ & $11.1 \mathrm{c}$ & $4625.5 \mathrm{c}$ \\
\hline
\end{tabular}

Means having similar letters have no significant difference at $5 \%$ probability level through Duncan multiple range test

By increasing the depletion of soil available water content internal $\mathrm{CO}_{2}$ concentration decreased in all treatments, so that it was at the lowest level under mild stress condition (60\% soil moisture depletion). But this decrease value in mycorrhizal inoculation, methanol application and combined treatment was less than control (Fig. 4a). By increasing the stress intensity and increasing the percentage of soil moisture depletion to values higher than $60 \%$, the amount of carbon dioxide covered by the intestinal space gradually increased in all treatments and increased to extreme stress (80\% soil moisture depletion). However, the internal $\mathrm{CO}_{2}$ concentration in the case of mycorrhizal inoculation and methanol spraying was less than control (Fig. 4a). Under normal irrigation conditions, stomatal conductance of leaves in Dena cultivar was more than Aflak and Alvand cultivars (Fig. 2b). Leaf transpiration rate in Aflak cultivar was more than Alvand cultivar, while transpiration rate in Dena and Alvand cultivars and Aflak and Dena cultivars showed no significant difference (Fig. 3b). Internal $\mathrm{CO}_{2}$ concentration under normal irrigation showed no significant difference. Under mild and 
severe stress conditions, stomatal conductance in Aflak and Dena cultivars was more than in Alvand cultivar (Fig. 2b). Under severe stress conditions, internal $\mathrm{CO}_{2}$ concentration increased for all cultivars compared to normal irrigation, but $\mathrm{CO}_{2}$ concentration in Aflak and Dena cultivars was less than in Alvand cultivar (Fig. 4b).

Under mild stress conditions, transpiration in Aflak and Dena cultivars was more than in Alvand. Under severe stress, there was no significant difference among three cultivars and Dena and Alvand cultivars had the highest and the lowest transpiration rate, respectively (Fig. $3 b$ ). Mild stress decreased internal $\mathrm{CO}_{2}$ concentration for three studied cultivars compared to normal irrigation. However, decreasing value in Aflak and Dena cultivars was less than in Alvand which could be attributed to higher drought resistance of cultivars. Severe stress resulted in increasing $\mathrm{CO}_{2}$ (Fig. $4 b$ ).
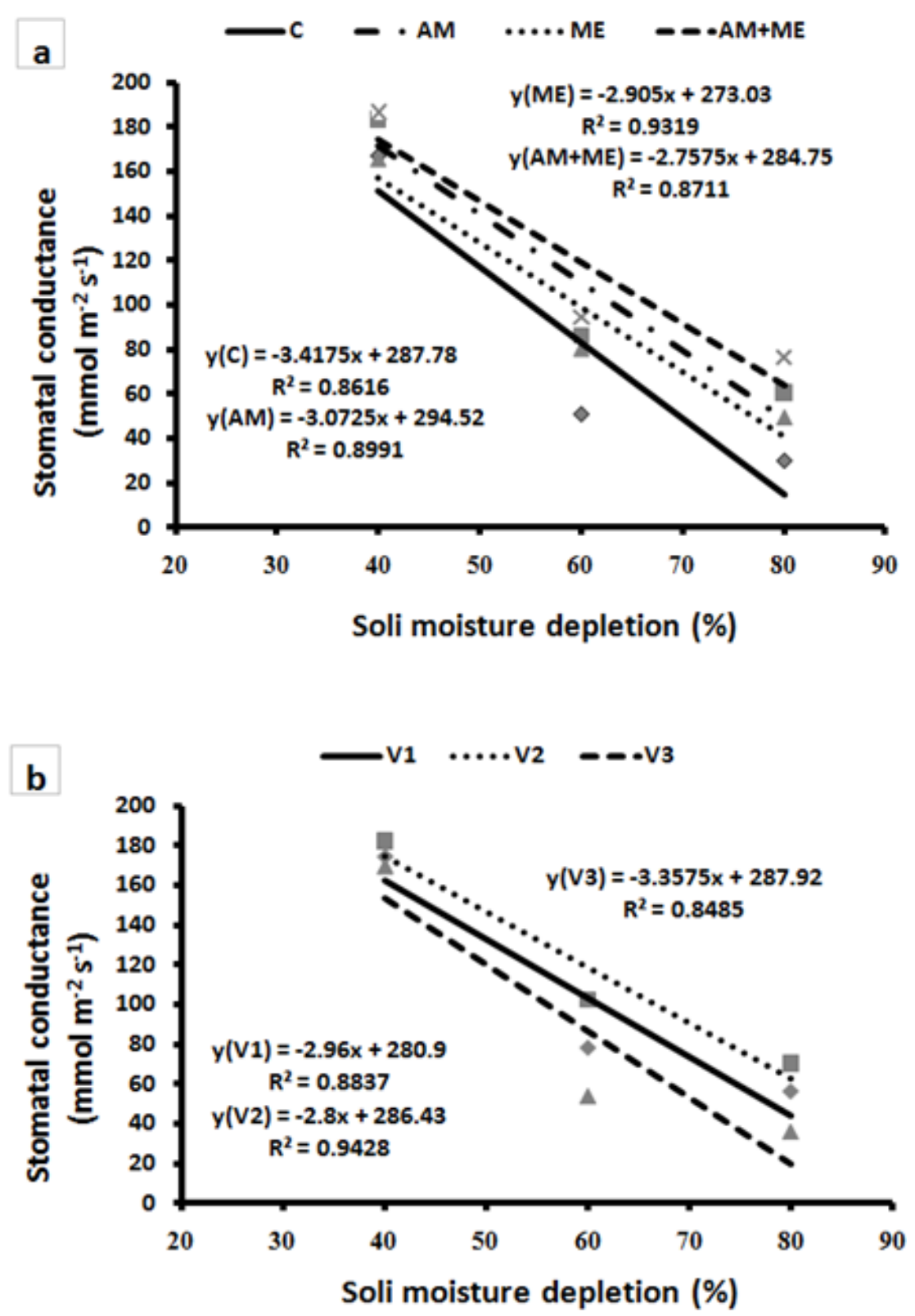

Figure 2. Regression curve for interaction of irrigation levels $\times$ mycorrhiza-methanol (a), irrigation levels $\times$ cultivar (b) on leaf stomatal conductance. (C: control, AM: mycorrhizal inoculation, ME: methanol spraying, $V_{1}$ : Aflak, $V_{2}$ : Dena, $V_{3}$ : Alvand) 


$$
-3791 \text { - }
$$
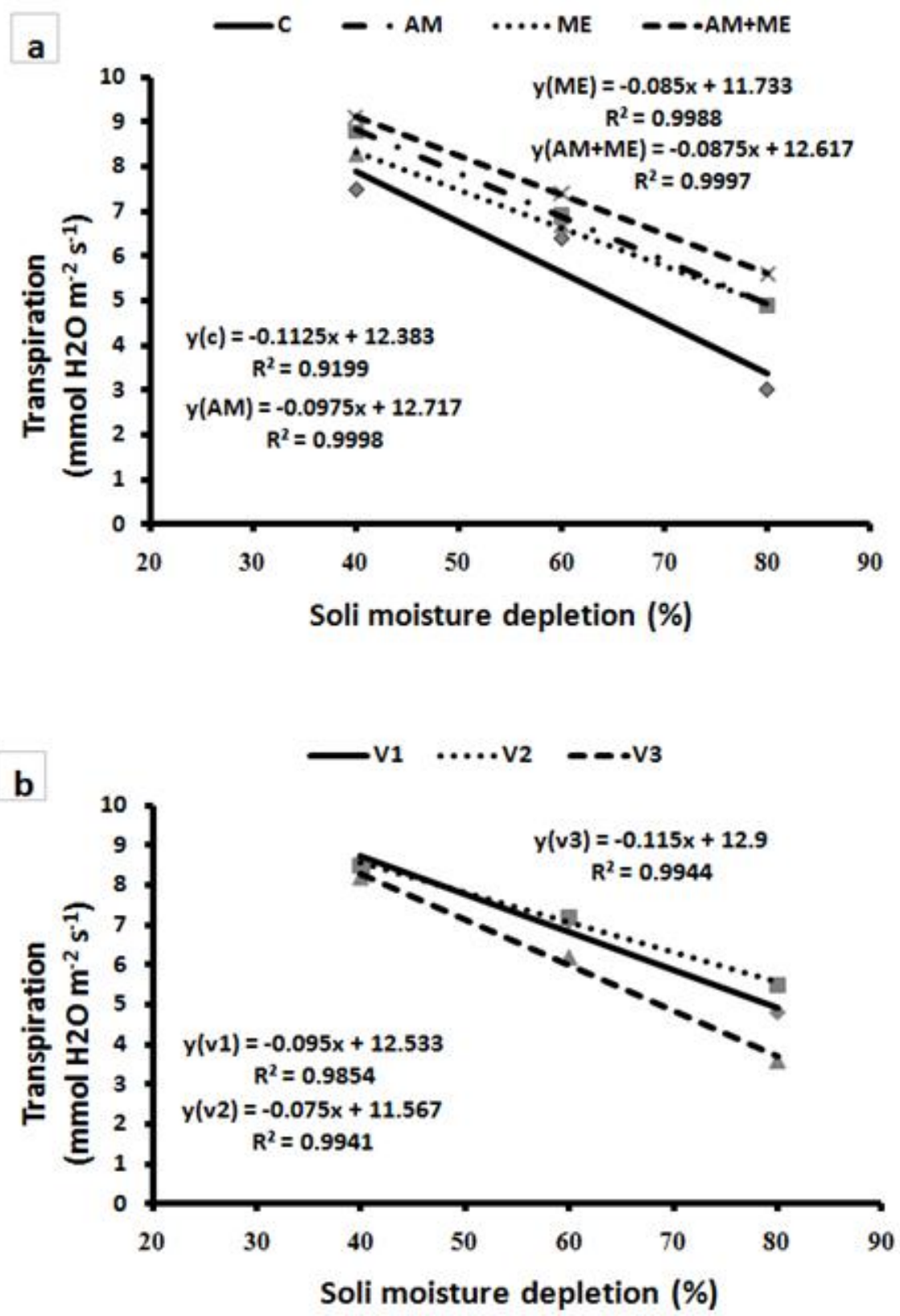

Figure 3. Regression curve for interaction of irrigation levels $\times$ mycorrhiza-methanol (a), irrigation levels $\times$ cultivar (b) on leaf transpiration. (C: control, AM: mycorrhizal inoculation, $M E$ : methanol spraying, $V_{1}:$ Aflak, $V_{2}:$ Dena, $V_{3}:$ Alvand)

\section{Photosynthetic rate}

Increasing depletion of plant available water under normal irrigation up to $60 \%$ and $80 \%$ and increasing stress level resulted in the decrease of photosynthestic rate in all treatments which the highest decrease observed in $80 \%$ moisture depletion. The highest deceasing trend devoted to control and the lowest was for methanol+mycorrhiza application. At all irrigation levels, photosynthetic rate in mycorrhizal inoculation, methanol spraying and combined application treatment was more than in the control (Fig. 5a). 

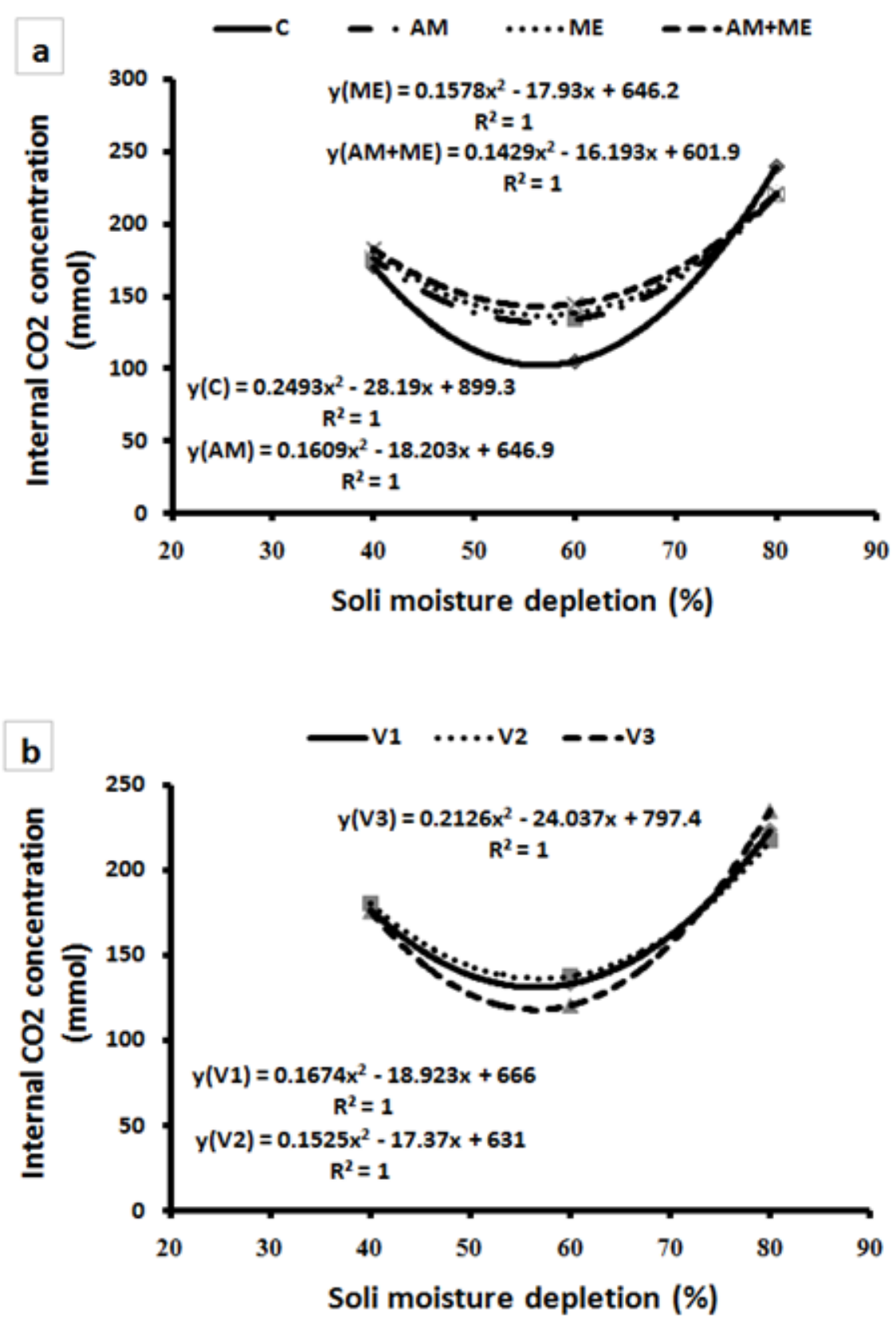

Figure 4. Regression curve for interaction of irrigation levels $\times$ mycorrhiza-methanol (a), irrigation levels $\times$ cultivar (b) on Internal $\mathrm{CO}_{2}$ concentration. (C: control, AM: mycorrhizal inoculation, $M E$ : methanol spraying, $V_{1}:$ Aflak, $V_{2}$ : Dena, $V_{3}$ : Alvand)

According to our results, effect of water deficit stress on stomatal conductance was significant (Table 3). Mild and severe water deficit stresses resulted in the decrease of stomatal conductance compared to normal irrigation (Table 4); therefore, one of the effective factors on declining photosynthetic rate in the current study could be stated as decrease in stomatal conductance at both mild and severe stress conditions. The positive and significant correlation between photosynthesis and stomatal conductance (Table 5) confirms that decrease in stomatal conductance causes decrease in photosynthetic rate.

Increasing depletion of plant available water under normal irrigation up to $60 \%$ and $80 \%$ and increasing stress level resulted in the decrease of photosynthetic rate and the 


$$
-3793-
$$

highest decrease was at $80 \%$ moisture depletion (severe stress), however decrease in Aflak and Dena cultivars was less than in Alvand. The highest decreasing trend was observed in Alvand and the lowest in Dena (Fig. 5b).
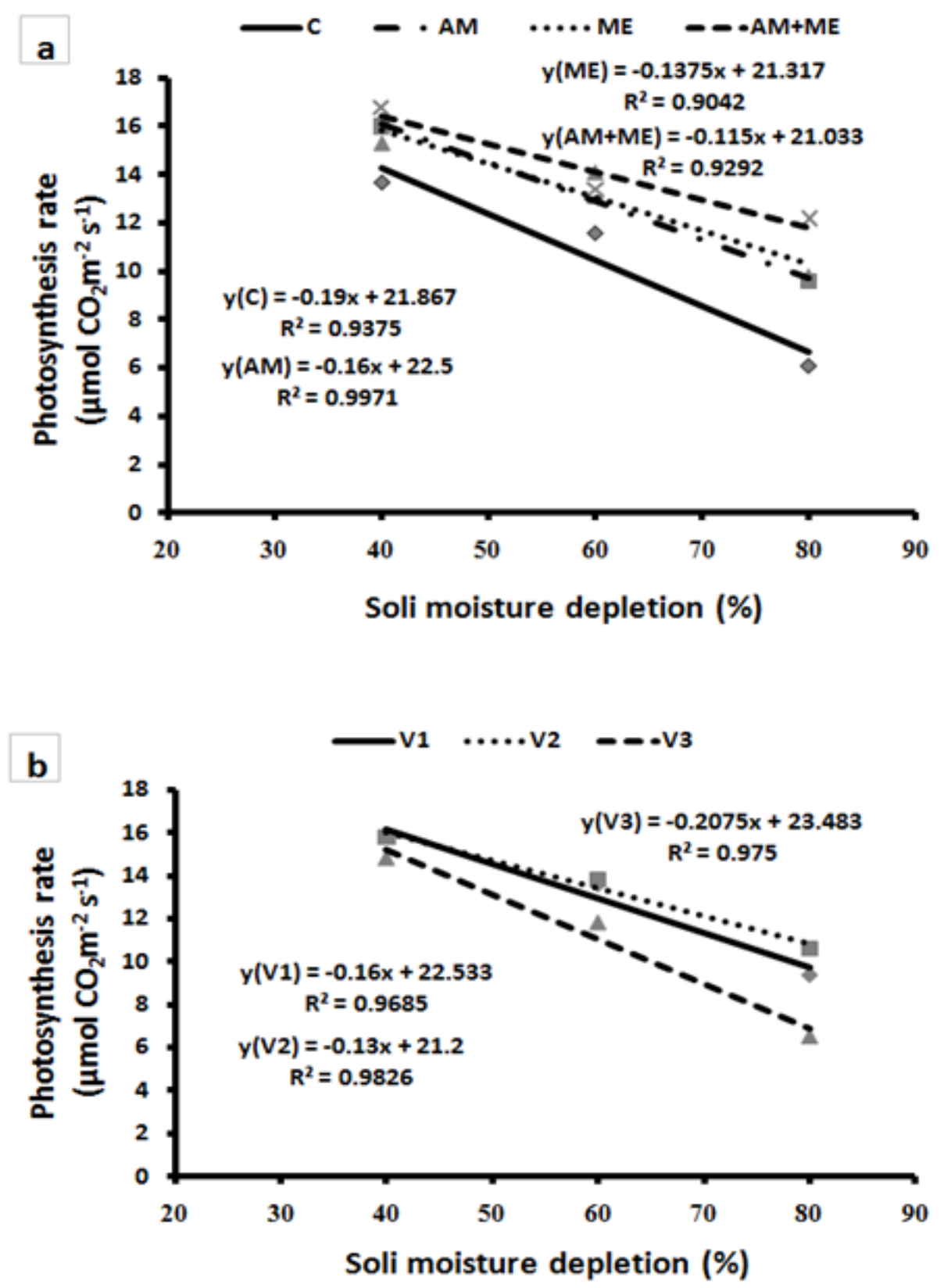

Figure 5. Regression curve for interaction of irrigation levels $\times$ mycorrhiza-methanol (a), irrigation levels $\times$ cultivar (b) on leaf photosynthetic rate. (C: control, AM: mycorrhiza inoculation, ME: methanol spraying, V1: Aflak, V2: Dena, V3: Alvand)

\section{Grain yield}

Interaction of water deficit stress $\times$ mycorrhiza-methanol and water deficit stress $\times$ cultivar on grain yield were significant (Table 3). Grain yield under mild and severe stress conditions decreased by $12.6 \%$ and $30 \%$ compared to normal irrigation, 
respectively (Table 4). Increasing depletion of plant available water under normal irrigation up to $60 \%$ and $80 \%$ and increasing stress level resulted in yield reduction for all studied treatments and highest decrease was at $80 \%$ moisture depletion. The greatest decreasing trend observed in control and the lowest in combined treatment application. At all irrigation levels grain yield in mycorrhizal inoculation, methanol spraying and combined treatment was more than in the control (Fig. 6a).
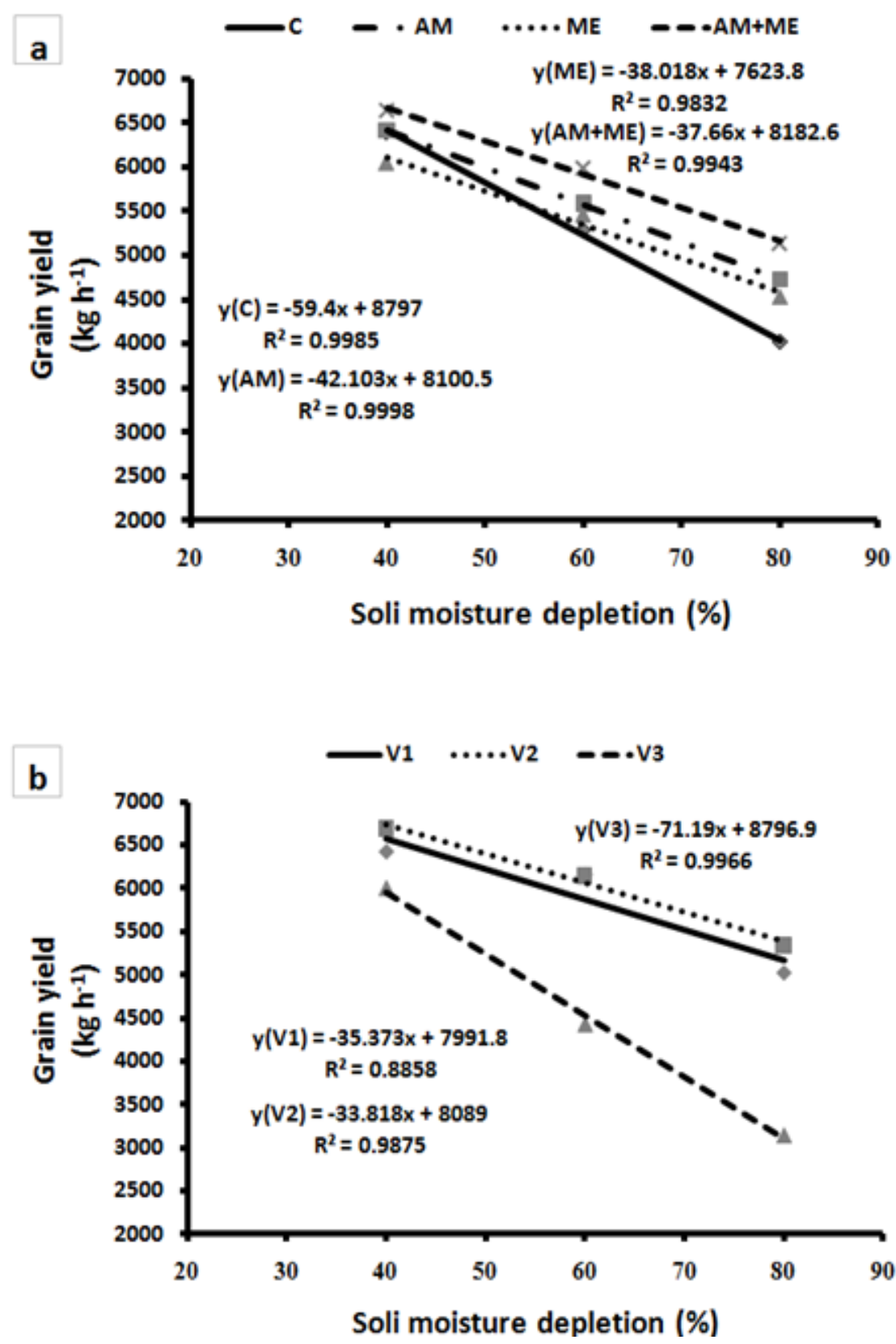

Figure 6. Regression curve for interaction of irrigation levels $\times$ mycorrhiza-methanol (a), irrigation levels $\times$ cultivar (b) on leaf photosynthetic rate. (C: control, AM: mycorrhiza inoculation, ME: methanol spraying, V1: Aflak, V2: Dena, V3: Alvand)

Increasing depletion of plant available water under normal irrigation up to $60 \%$ and $80 \%$ and increasing stress intensity resulted in the decrease of grain yield and the 
highest decrease was at $80 \%$ moisture depletion; however, decrease in Aflak and Dena cultivars were less than in Alvand. The highest decreasing trend was in Alvand cultivar and the lowest in Dena cultivar (Fig. 6b).

Mean comparisons showed that in control treatment, all studied cultivars had significant difference in terms of grain yield and the highest and the lowest yield associated to Dena and Alvand, respectively. Aflak and Dena cultivars reacted well to mycorrhizal inoculation, so that their yield increased by $12.8 \%$ and $7 \%$ compared to control, while there was no significant difference in yield of Alvand between control and mycorrhizal inoculation treatments. Studied cultivars had different response to methanol application. Aflak and Dena had no significant difference in terms of grain yield in methanol spraying, but Aflak showed $7.1 \%$ increase compared to the control (Fig. 7).

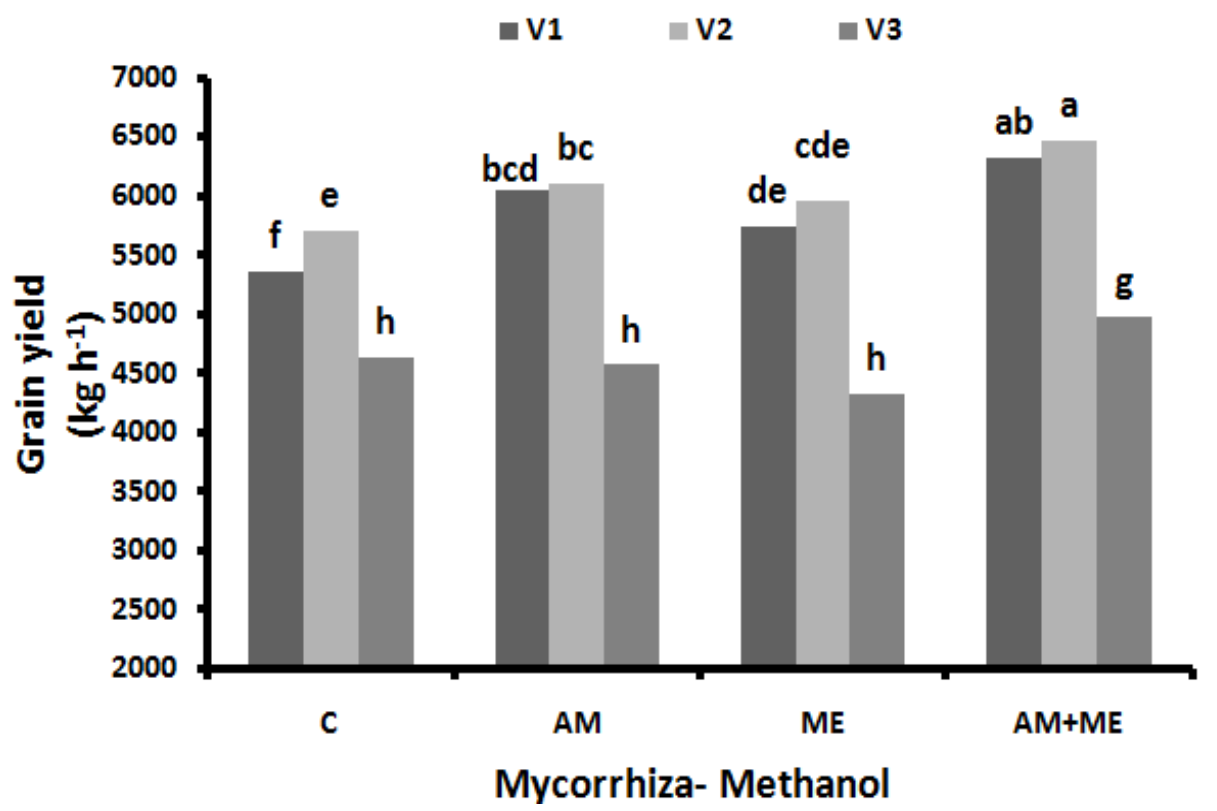

Figure 7. Mean comparisons for interaction of mycorrhiza- methanol $\times$ cultivar on grain yield (e). Means having similar letters have no significant difference at $5 \%$ probability level through Duncan multiple range test. (C: control, AM: mycorrhiza inoculation, ME: methanol spraying, V1: Aflak, V2: Dena, V3: Alvand)

\section{Discussion}

\section{Leaf gas exchange}

Siddique et al. (1999) found that wheat plants under drought stress conditions had considerable decrease in photosynthetic rate and stomatal conductance. Allahverdiyev and Huseynova (2017) report stomatal conductance, net photosynthetic rate and transpiration rate decreased significantly in flag leaves of wheat genotypes in response to drought stress at anthesis. Possibly increase in stomatal conductance in methanol spraying under water deficit conditions could be attributed to methanol contribution in enhancing stomata cells turgor and decrease in stomata closure. Nonomura and Benson (1992) concluded that methanol spraying in plant aerial parts increased plant turgor and prevented leaves subjected to direct sunlight from wilting, especially in hot regions. Zheng et al. (2008) reported that methanol spraying caused an increase in stomatal 
conductance and wheat plant photosynthesis. In a study conducted on cotton plants in Pakistan dry areas, methanol spraying resulted in the increase of stomatal conductance in treated plants (Makhdum et al., 2002). Zheng et al. (2008) found that methanol spraying increased wheat plant transpiration. Mycorrhizal symbiosis caused to delay in declining water content in leaves during drought stress and therefore stomata could be open for a longer period (Simpson and Duff, 1990). In another study on bean plants conducted by Zlatov and Yordanov (2004) resulted that intracellular $\mathrm{CO}_{2}$ concentration decreases under drought stress conditions, which closes the leaf stomata and prevents the entry of $\mathrm{CO}_{2}$ into the leaves. Arbuscular mycorrhiza stimulation of carbon exchange rate, stomatal conductance, and transpiration rate has been significant (Auge et al., 2016). Arbuscular mycorrhizal (AM) symbiosis often modifies gas exchange of the host plant (Koide, 1993; Smith and Read, 2008; Ruiz-Lozano and Aroca, 2010; Auge et al., 2014).

It was found that higher drought stress resistance in wheat cultivars is associated to higher stomatal conductance and partially to mesophilic conductance (Siosehmardeh et al., 2004). Difference in transpiration rate could be due to difference in sensitivity and tolerance rate of these cultivars to drought stress and stomatal reactions to water deficiency. Aflak and Dena cultivars kept their stomata less closed due to drought stress tolerance and had higher stomatal conductance and consequently had greater transpiration. Resistant wheat genotypes to drought having higher transpiration rate under drought stress conditions are able to uptake more water from soil and have higher leaf water content. Consequently, these genotypes have higher stomatal conductance and transpiration rate in comparison with drought sensitive cultivars. Roohi and Siosemardeh (2008) reported that leaf stomatal conductance and transpiration in resistant wheat genotypes was higher than in sensitive genotypes under water deficit conditions by $27 \%$ and $24 \%$, respectively. The intercellular $\mathrm{CO}_{2}$ concentration in flag leaf of most genotypes increased under drought condition (Allahverdiyev and Huseynova, 2017). It appears that Aflak and Dena had stomata openness ability due to drought stress resistance and therefore decrease in internal $\mathrm{CO}_{2}$ concentration under mild stress condition was lower than in Alvand which had lower drought stress resistance. Also, these cultivars had lower destructive impact of severe stress conditions on biochemical processes and owing to higher mesophilic conductance, internal $\mathrm{CO}_{2}$ concentration was lower than in Alvand. Mild drought stress reduces photosynthesis through reversible stomatal factors. Under more severe or prolonged stress conditions, non-stomatal factors aggravate unfavorable conditions and the effects of stress generally become irreversible (Ahmadi and Baker, 2000). Decrease in photosynthesis under higher drought levels is due to destructive biochemical processes (Johnston and Fowler, 2002). Photosynthesis limiting factors divided into stomatal factors which cause decrease in $\mathrm{CO}_{2}$ diffusion into intercellular space due to decrease in stomatal conductance and non-stomatal factors which limit photosynthetic rate through direct impact of water deficit on carbon processing biochemical processes (Ahmadi and Baker, 2000).

\section{Photosynthetic rate}

The damage caused by drought to plants is primarily attributed to the inhibition and disruption of photosynthesis, which is the main mechanism of plant growth and maintenance of natural environments, and it threats to the growth and yields of plants (Shao et al., 2016). Siddique et al. (1999) concluded that wheat plants under drought 
stress had considerable decrease in stomatal conductance and photosynthetic rate. It appears that methanol foliar application resulted in the increase of $\mathrm{CO}_{2}$ concentration in leaf cells and largely compensated $\mathrm{CO}_{2}$ deficit and prevented further decrease in photosynthesis under drought stress conditions. Methanol, in comparison with $\mathrm{CO}_{2}$, is a smaller molecule which could be easily utilized by $\mathrm{C}_{3}$ plants for increasing photosynthetic rate (Li et al., 1995; Kotzabasis et al., 1999). Increase in photosynthetic rate through methanol foliar application has been reported by many authors (Setua et al., 2009; David et al., 2003). Zheng et al. (2008) studied the effect of methanol foliar application at various concentrations on winter wheat and reported that methanol increased stomata conductance, transpiration rate, internal $\mathrm{CO}_{2}$ concentration and photosynthesis rate. It appears that methanol impact on $\mathrm{C}_{3}$ plants is due to decrease in their photorespiration, because under filed conditions when air temperature, light intensity and consequently photorespiration were high, methanol foliar application increased plant growth (Nonomura and Benson, 1992; Fall and Benson, 1996). Photosynthesis rate in mycorrhizal plants was more than non-mycorrhizal plants which could be resulted from the effect of mycorrhiza on stomata opening. It is known that plants subjected to water deficit stress decrease photosynthesis because of an accumulation of ROS that damages the photosynthetic apparatus (Abbaspour et al., 2012), which can limit the NADPH and ATP supply of the Calvin cycle. As a consequence of AMF symbiosis, plants improve the water status, which increases photosynthesis by increasing stomatal conductance and, therefore, $\mathrm{CO}_{2}$ fixation (Boldt et al., 2011). Relationship between the stomatal opening and the relative increase in the photosynthetic activity have been described in corn (Estrada et al., 2013). Mycorrhizal association has been shown to increase the carbon fixation abilities of the plants. In a number of systems, higher photosynthetic rates have been reported when the plants are in association with AM fungi. For instance, in black locust, Yang et al. (2014) observed high stomatal conductance, high transpiration rates and high photosynthetic rates with reduced internal $\mathrm{CO} 2$ concentration in fungal colonized plants than the non-colonized plants.

\section{Grain yield}

Drought is one of the critical environmental adversities affecting the growth, development and final yield of crop species (Geng et al., 2016; Daryanto et al., 2017), and the frequency and severity of drought stress events are expecting to increase due to global climate change (Cook et al., 2014; Zhao and Dai, 2015; Joshi et al., 2016). Drought stress perturbs a broad range of plant physiological and biochemical processes, including decreased plant water status, inhibited photosynthetic processes, induced oxidative stress damage and so on, which ultimately lead to growth retardation and the reduction of crop yield (Perdomo et al., 2015; Saeidi and Abdoli, 2015; Daryanto et al., 2017). It can be inferred that mycorrhizal inoculation and methanol application under mild and severe drought stress conditions inhibited from decrease in grain yield and lead to decreased and mediated damages due to water deficit stress in wheat crop. Under water stress conditions, mycorrhizal inoculated wheat plants produced better yield than control. It can be concluded that under moisture stress, mycorrhiza had effective contribution and increased water and nutrient uptake from soil through developing hypha and fungi mycelium and prevented from decrease in growth and grain yield under drought stress conditions. Mycorrhiza treatment improved all of wheat growth traits and drought resistance (Abo-ghalia and Khalafallah., 2008). Mycorrhiza fungi establish 
symbiotic association with roots of many plants cause increase in nutrient and water uptake, alleviating negative impacts of environmental stresses and improvement in plant growth and yield in sustainable agriculture systems (Sharma, 2002). Al-Karaki et al. (2004) concluded that under normal irrigation and drought stress conditions, mycorrhiza improved wheat grain yield and biomass and had great contribution in alleviating impacts of drought stress in field conditions. Some authors reported that methanol foliar application had no significant difference on most of studied traits in wheat (Milton et al., 1995; Ekiz et al., 1996). Contrarily, some authors reported that methanol spraying improved wheat growth and yield (Nonomura and Benson, 1992; Zheng et al., 2008). Other studies have shown that methanol application in crop plants under water deficit increased their biomass, while treating water-supplied plants with methanol, decreased their biomass (Nonomura and Benson, 1992; Ramirez et al., 2006).

Results of the present study revealed positive and significant correlation among grain yield with photosynthetic rate $(\mathrm{r}=0.84)$, stomatal conductance $(\mathrm{r}=0.86)$ and transpiration rate $(\mathrm{r}=85)$ (Table 5). Grain yield under moisture stress decreased photosynthetic rate and stomatal conductance increased, while in mycorrhizal inoculation, methanol spraying and combined treatments, grain yield decreased less compared to control due to higher photosynthetic rate and stomatal conductance (Figs. $6 a, 1 a$ and $5 a)$.

Table 5. Correlation of grain yield with photosynthetic rate and leaf gas exchanges under mild and severe water deficit stress conditions

\begin{tabular}{c|c|c|c|c|c}
\hline Traits & GY & SC & ICC & PR & LT \\
\hline Grain yield (GY) & 1 & & & & \\
Stomatal conductance (SC) & $0.86^{* *}$ & 1 & & & \\
Internal $\mathrm{CO}_{2}$ concentration (ICC) & $-0.46^{*}$ & $-0.36 \mathrm{~ns}$ & 1 & & \\
Photosynthesis rate (PR) & $0.84^{* *}$ & $0.83^{* *}$ & $-0.77^{* *}$ & 1 & \\
Leaf transpiration (LT) & $0.85^{* *}$ & $0.82^{* *}$ & $-0.76^{* *}$ & $0.97^{* *}$ & 1 \\
\hline
\end{tabular}

$\mathrm{ns}, *$, and $* *$ are non-significant, significant at $5 \%$ and $1 \%$ probability levels, respectively.

Under mild and severe stress conditions, yield for all studied cultivars decreased compared to normal irrigation, but decreasing value in Alvand $(26.1 \%$ and $42.5 \%$, respectively) was more than in Aflak (4.2\% and $22 \%$ respectively) and in Dena $(8.1 \%$ and $20.2 \%$, respectively) cultivars (Table 4), which could be due to the fact that Alvand is a late maturing cultivar and the observed decrease represents more sensitivity of Alvand to late season water deficit stress. Karimzadeh Shurshjani et al. (2012) reported that Durum wheat cultivars, being early mature had less yield decrease compared to bread wheat cultivars under late season drought and yield decrease was higher in drought sensitive cultivars. Other authors have reported significant reductions in wheat yield due to late season drought stress (Dastfal et al., 2009; Gonzalez et al., 2010). The reason for decreasing grain yield for Alvand cultivar compared two other ones is that stomatal conductance, leaf tranpiration and photosynthetic rate decreased more under mild and severe drought stress conditions (Figs. $1 b, 2 b$ and $5 b$ ). These results show that Alvand cultivar is more vulnerable to late season drought stress than other cultivars. Siosemardeh et al. (2005) found that decrease in stomatal conductance and mesophyll conductance and consequently decrease in photosynthetic rate are the main factors 
affecting yield of various wheat cultivars under drought stress conditions and resistant cultivars have higher stomatal conductance and mesophyll conductance as well as photosynthetic rate than sensitive cultivars.

Ekiz et al. (1996) understood that yield of irrigated wheat cultivars had no significant difference in methanol spraying treatments. In combined treatments, there was no significant difference between Aflak and Dena, while Alvand had lower yield than other two cultivars. Yield of cultivars studied increased compared to control in combined treatment. Results of other studies represent various responses of wheat cultivars to mycorrhizal inoculation (Vierheilig and Ocampo, 1991).

\section{Conclusion}

According to the results obtained, it can be concluded that late season drought stress caused decrease in stomatal conductance, leaf transpiration, photosynthetic rate and increase in internal $\mathrm{CO}_{2}$ concentration and consequently decreased grain yield of wheat, while mycorrhizal inoculation and methanol spraying alleviated negative impacts of water stress and improved photosynthetic rate and leaf gas exchanges compared to control under drought stress conditions and consequently increased grain yield. Also, the differential response of cultivars to imposed water stress condition indicates the drought tolerance ability of wheat cultivars. Results showed that cultivar and vulnerability rate and their tolerance are effective in wheat response to late season drought stress. Decrease in photosynthetic rate, gas exchanges and yield in Alvand cultivar under mild and severe drought stress was more than in Aflak and Dena cultivars; that represent sensitivity of Alvand cultivar to late season drought stress conditions. In total, it can be concluded that use of drought-tolerant wheat cultivars cause decrease in destructive impacts of terminal season drought stress. Also, mycorrhizal application and methanol spraying improve photosynthesis, leaf gas exchanges and grain yield and could be considered as cropping management strategies for decreasing damages of late season drought stress in irrigated wheat crop systems. In the future studies, it is recommended for evaluation of effect of milder levels of water deficit stress on the growth and yield of wheat, because severe stress have a lot of negative impact on leaf gas exchange and growth, and the sharp decline in wheat yield.

\section{REFERENCES}

[1] Abbaspour, H., Saeidi-Sar, S., Afshari, H., Abdel-Wahhab, M. (2012): Tolerance of mycorrhiza infected pistachio (Pistacia vera L.) seedling to drought stress under glasshouse conditions. - J. Plant Physiol. 169: 704-709.

[2] Abo-Ghalia, H. H., Khalafallah, A. A. (2008): Responses of wheat plants associated with arbuscular mycorrhizal fungi to short-term water stress followed by recovery three growth stages. - J. Appl. Sci. Res. 4: 570-580.

[3] Ahmadi, A. Baker, D. A. (2000): Stomatal and non-stomatal factors limiting photosynthesis in wheat under drought stress conditions. - Iranian Journal of Agricultural Sciences 31(4): 813-825.

[4] Al-Karaki, G. N., McMichael, B., Zak, J. (2004): Field response of wheat to arbuscular mycorrhizal fungi and drought stress - Mycorrhiza 14: 263-269.

[5] Allahverdiyev, T., Huseynova, I. (2017): Influence of water deficit on photosynthetic activity, dry matter partitioning and grain yield of different durum and bread wheat genotypes. - Cereal Research Communications 45(3): 432-441. 
[6] Altenbach, S. B., Dupont, F. M., Kothari, K., Chan, K. M. Johanson, R., Lieu, D. (2003): Temperature, water and fertilizer influence the timing of key events during grain development in US spring wheat. - Journal of Cereal Science 37: 9-20.

[7] Aroca, R. (2012): Plant Responses to Drought Stress: From Morphological to Molecular Features. - Springer-Verlag, Berlin.

[8] Auge, R. M. (2001): Water relations, drought and vesicular - arbuscular mycorrhiza symbiosis. - Mycorrhiza 11: 3-42.

[9] Auge, R. M., Saxton, A. M., Toler, H. D. (2014): Arbuscular mycorrhizal symbiosis alters stomatal conductance of host plants more under drought than under amply watered conditions: a meta-analysis. - Mycorrhiza 25: 13-24.

[10] Auge, R. M., Toler, D. H., Saxton, A. M. (2016): Mycorrhizal stimulation of leaf Gas exchange in relation to root colonization, shoot size, leaf phosphorus and nitrogen: A quantitative analysis of the literature using meta-regression. - Frontiers in Plant Science 7: $1-16$.

[11] Blum, A., Gozlan, G., Mayer, J. (1981): The manifestation of dehydration avoidance in wheat breeding germplasm. - Crop Sci 21: 495-499.

[12] Boldt, K., Pors, Y., Haupt, B., Bitterlich, M., Kuhn, C., Grimm, B., Franken, P. (2011): Photochemical processes, carbon assimilation and RNA accumulation of sucrose transporter genes in tomato arbuscular mycorrhiza. - J. Plant Physiol. 168: 1256-1263.

[13] Cook, B. I., Smerdon, J. E., Seager, R., Coats, S. (2014): Global warming and 21st century drying. - Clim. Dynam. 43: 2607-2627.

[14] Dar, Z. M., Masood, A., Asif, M., Malik, M. A. (2018): Review on arbuscular mycorrhizal fungi: An approach to overcome drought adversities in plants. - International Journal of Current Microbiology and Applied Science 7(3): 1040-1049.

[15] Daryanto, S., Wang, L., Jacinthe, P. A. (2017): Global synthesis of drought effects on cereal, legume, tuber and root crops production: a review. - Agric. Water Manage. 179: 18-33.

[16] Dastfal, M., Barati, V., Navabi, F., Haghighatnia, H. (2009): Effect of drought stress on yield and its components in bread wheat genotypes under dry and arid conditions in southern fars province. - Iranian Journal of Seedling and Seed Improvement 2-25(30): 331-346.

[17] David, D., Claire, D., Phillippe, J., Guy, V. Radovan, P. (2003): Effects of methanol on photosynthetic processes and growth of Lemna gibba. - Photochemistry and Photobiology 78: 420-424.

[18] Downie, A., Miyazaki, S., Bohnert, H., John, P., Coleman, J., Parry, M., Haslam, R. (2004): Expression profiling of the response of Arabidopsis thaliana to methanol stimulation. - Phytochem. 65: 2305-2316.

[19] Ekiz, H., Ahmet Bagci, S., Safi Kiral, A. (1996): Effects of foliar methanol. applications on yield of bread wheat cultivars grown under field conditions. - J. Cereal Research Communications 24(3): 369-375.

[20] Estrada, B., Aroca, R., Barea, J. M., Ruiz-Lozano, J. M. (2013): Native arbuscular mycorrhizal fungi isolated from a saline habitat improved maize antioxidant systems and plant tolerance to salinity. - Plant Sci. 201/202: 42-51.

[21] FAO (2012): Coping with Water Scarcity: An Action Framework for Agriculture and Food Security. - FAO Water Reports No. 38, Rome, Italy.

[22] Garcia-Sanchez, M., Palma, J. M., Ocampo, J. A., Garcia-Romera, I., Aranda, E. (2014): Arbuscular mycorrhizal fungi alleviate oxidative stress induced by ADOR and enhance antioxidant responses of tomato plants. - J. Plant Physiol. 171: 421-428.

[23] Geng, G., Wu, J., Wang, Q., Lei, T., He, B., Li, X. (2016): Agricultural drought hazard analysis during 1980-2008: a global perspective. - Int. J. Climatol. 36: 389-399.

[24] Gholamhoseini, M., Ghalavand, A., Dolatabadian, A., Jamshidi, E., Khodaei-Joghan, A. (2013): Effects of arbuscular mycorrhizal inoculation on growth, yield, nutrient uptake 
and irrigation water productivity of sunflowers grown under drought stress. - Agric. Water Manag. 117: 106-114.

[25] Gonzalez, A., Bermejo, V., Gimeno, B. S. (2010): Effect of different physiological traits on grain yield in barley grown under irrigated and terminal water deficit conditions. - J. Agric. Sci. Cam. 148: 319-328.

[26] Huseynova, I. M., Rustamova, S. M., Suleymanov, S. Y., Aliyeva, D. R., Mammadov, A. C., Aliyev, J. A. (2016): Drought-induced changes in photosynthetic apparatus and antioxidant components of wheat (Triticum durum Desf.) varieties. - Photosynth. Res. 130: 215-223.

[27] Jalal Kamali, M., Asadi, R. H., NajafiMirak, T., Aghaee, M. (2012): Wheat: Research and Management Strategies in Iran. - Nashr-e-Amuzesh Keshavarzi Publications, Karaj.

[28] Johnston, A. M., Fowler, D. E. (1992): Response of no-till winter wheat to nitrogen fertilization and drought stress. - Can. J. Plant Sci. 72: 1075-1089.

[29] Joshi, R., Wani, S. H., Singh, B., Bohra, A., Dar, Z. A., Lone, A. A. (2016): Transcription factors and plants response to drought stress: current understanding and future directions. - Front. Plant Sci. 7: 1029.

[30] Karimzadeh Surshjani, H., Emam, Y., Muri, S. (2012): Response of Yield, Yield Components and Indicators of Tolerance of Bread Wheat Cultivars and Durum Wheat to Post-Flowering Drought Stress. - Journal of Iranian Crop Sciences 1: 151-162.

[31] Koide, R. (1993): Physiology of the mycorrhizal plant. - Adv. Plant Pathol. 9: 33-54.

[32] Kotzabasis, K., Hatziathanasiou, A., Bengoa Ruigomez, M. V., Kentouri, M., Divanach, P. (1999): Methanol as alternative carbon source for quicker efficient production of the microalgae Chlorella minutissima: role of the concentration and frequence of administration. - J. Biotechno. 70: 357-362.

[33] Li, C., Yue, J., Wu, X., Xu, C., Yu, J. (2014): An ABA-responsive DRE-binding protein gene from Setaria italica, SiARDP, the target gene of SiAREB, plays a critical role under drought stress. - Journal of Experimental Botany 65: 5415-5427.

[34] Li, Y., Gupta, J., Siyumbano, A. K. (1995): Effect of methanol on soybean photosynthesis and chlorophyll. - J. Plant Nutr. 18: 1875-1880.

[35] Makhdum, M. I., Malik, M. N. A., Din, Sh., Ahmad, F., Chaudhry, F. I. (2002): Physiological response of cotton to methanol foliar application. - J. Research in Science Pakistan 13: 37-43.

[36] Milton, E., McGiffen, M. E., Green, R. L., Manthey, J. A., Faber, B. A., Downer, A. J., Sakovich, N. J., Aguiar, J. (1995): Field tests of methanol as a crop yield enhancer. Hort. Sci. 30: 1225-1228.

[37] Mir, R. R., Zaman-Allah, M., Sreenivasulu, N., Trethowan, R., Varshney, R. K. (2012): Integrated genomics, physiology and breeding approaches for improving drought tolerance in crops. - Theor Appl. Genet. 125: 625-645.

[38] Mirakhori, F., Paknejad, F., Moradi, F., Ardakani, M., Zahedi, H., Nazeri, P. (2009): Effect of drought stress and methanol on yield and yield components of soybean max (L17). - American Journal of Biochemistry and Biotechnology 5: 162-169.

[39] Nonomura, A. M., Beson, A. A. (1992): The path to carbon in photosynthesis: improved crop yields with methanol. - Proc. Natl. Acad. Sci. U.S.A 89: 9794-9798.

[40] Perdomo, J. A., Conesa, M. A., Medrano, H., Ribas-Carbo, H., Galmes, M. J. (2015): Effects of long-term individual and combined water and temperature stress on the growth of rice, wheat and maize: relationship with morphological and physiological acclimation. - Physiol. Plant. 155: 149-165.

[41] Rajala, A., Karkkainen, J., Peltonen, J., Pelto-nen-Sainio, P. (1998): Foliar applications of alcohols failed to enhance growth and yield of $\mathrm{C}_{3}$ crops. - Industrial Crops and Products 7: 129-137.

[42] Ramberg, H. A., Bradley, J. S. C., Olson, J. S. C., Nishio, J. N., Markwell, J., Osterman, J. C. (2002): The role of methanol in promoting plant growth: an update. - Plant Biochemistry and Biotechnology 1: 113-126. 
[43] Ramirez, I., Dorta, F., Espinoza, V., Jimenez, E., Mercado, A., Pen Cortes, H. (2006): Effects of foliar and root applications of methanol on the growth of Arabidopsis, tobacco and tomato plants. - J. Plant Growth Regul 25: 30-44.

[44] Rauf, M., Munir, M., Hassan, M., Ahmad, M., Afzal, M. (2007): Performance of wheat genotypes under osmotic stress at germination and early seedling growth stage. - African J. of Agric Res. 6: 971-975.

[45] Roohi, E., Siosemardeh, A. (2008): Study on gas exchange in different wheat (Triticum aestivum L.) genotypes under moisture stress conditions. - Seed and Plant Improvement Journal 24(1): 45-62.

[46] Ruiz-Lozano, J. M., Aroca, R. (2010): Host Response to Osmotic Stresses: Stomatal Behavior and Water Use Efficiency of Arbuscular Mycorrhizal Plants. - In: Koltai. H., Kapulnik., Y. (eds.) Arbuscular Mycorrhiza: Physiology and Function, 2nd edn. SpringerVerlag, Dordrecht, pp. 239-256.

[47] Saeidi, A., Akbari, A., Bakhtiar, F., Mehrvar, M., Nategh, Z. (2005): Specifications of Bread Wheat Cultivars, Durum Wheat, Barley, Triticale and Rye Introduced by the Cereal Research Sector. - Seed and Plant Improvement Research Institute Publications, Karaj, Iran.

[48] Saeidi, M., Abdoli, M. (2015): Effect of drought stress during grain filling on yield and its components, gas exchange variables, and some physiological traits of wheat cultivars. $-\mathrm{J}$. Agric. Sci. Technol. 17: 885-898.

[49] Setua, M., Setua, G. C., Debnath, S., Chakraborty, S., Bajpai, A. K. (2009): Effect of foliar application of methanol on growth and leaf yield in mulberry (Morus alba L.). Ann. Agric. Res. New Series 30(1/2): 59-61.

[50] Shao, G., Huang, D., Cheng, X., Cui, J., Zhang, Z. (2016): Path analysis of sap flow of tomato under rain shelters in response to drought stress. - Int. J. Agric. Biol. Eng. 9(2): 54-62.

[51] Sharma, A. K. (2002): Biofertilizers for Sustainable Agriculture. - Agrobios, Jodhpur, India.

[52] Sharma, P., Jha, A. B., Dubey, R. S., Pessarakli, M. (2012): Reactive oxygen species, antioxidative damage and oxidative defense mechanism in plants under stressful conditions. - Journal of Botany 2012: 1-26.

[53] Shewry, P. R. (2009): Wheat. - Journal of Experimental Botany 60: 1537-1553.

[54] Siddique, M. R. B., Hamid, A., Islam, S. (1999): Drought stress effect on photosynthetic rate and leaf gas exchange of wheat. - Bot. Bull. Acad. Sin. 40: 141-145.

[55] Siosehmardeh, A., Ahmadi, A., Pustini, K., Ebrahimzadeh, H. (2004): Photosynthesis controller and its relationship with drought tolerance in wheat cultivars. - Journal of Iranian Agricultural Sciences 35(1): 93-106.

[56] Siosemardeh, A., Ahmadi, A., Postini, K., Ebrahimzadeh, H. (2005): Stomatal and nonstomatal limitations to photosynthesis and their relationship with drought resistance in wheat cultivars. - Journal of Agricultural Science 35(1): 93-106.

[57] Simpson, D., Daff, M. J. (1990): Spore production and mycorrhizal development in various tropical crop hosts infected with Glomus clarum. - Plant Soil 121: 171-178.

[58] Smith, F. A., Grace, E. J., Smith, S. E. (2009): More than a carbon economy: nutrient trade and ecological sustainability in facultative arbuscular mycorrhizal symbioses. New Phytologist 182: 347-358.

[59] Smith, S. E., Read, D. (2008): Mycorrhizal Symbiosis, 3rd edn. - Elsevier, Amsterdam.

[60] Vierheilig, H., Ocampo, J. A. (1991): Susceptibility and effectiveness of vesiculararbuscular mycorrhizae in wheat cultivars under different growing conditions. - Biol. Fert. Soils 11: 290-294.

[61] Yang, Y., Chen, Y., Li, W. (2008): Arbuscular mycorrhizal fungi infection in desert riparian forest and its environmental implications: a case study in the lower reach of Tarim River. - Prog. Nat. Sci. 18: 983-991. 
[62] Yang, Y., Tang, M., Sulpice, R., Chen, H., Tian, S., Ban, Y. (2014): Arbuscular mycorrhizal fungi alter fractal dimension characteristics of Robinia pseudoacacia L. seedlings through regulating plant growth, leaf water status, photosynthesis, and nutrient concentration under drought stress. - Journal of Plant Growth Regulators 33: 612-625.

[63] Zhao, T. B., Dai, A. G. (2015): The magnitude and causes of global drought changes in the twenty-first century under a low-moderate emissions scenario. - J. Clim. 28: 44904512.

[64] Zheng, Y., Yang, Y., Liang, S., Yi, X. (2008): Effect of methanol on photosynthesis and chlorophyll fluorescence of flag leaves of winter wheat. - Agricultural Sciences in China 7(4): $432-437$.

[65] Zhu, X. C., Song, F. B., Liu, S. Q., Liu, T. D., Zhou, X. (2012): Arbuscular mycorrhizae improve photosynthesis and water status of Zea mays L. under drought stress. - Plant Soil and Environment 58(4): 186-191.

[66] Zlatev, Z. S., Yordanov, I. T. (2004): Effects of soil drought on photosynthesis and chlorophyll fluorescence in bean plants. - Bulgarian Journal of Plant Physiology 30: 318 . 